\title{
European Health Claims for Small and Medium-Sized Companies - Utopian Dream or Future Reality?
}

\author{
Sonja Brandenburger*, Marc Birringer \\ ${ }^{1}$ Department of Nutritional, Food and Consumer Sciences, University of Applied Sciences \\ Fulda, Fulda, Germany
}

*Corresponding author: Sonja Brandenburger, Department of Nutritional, Food and Consumer Sciences, University of Applied Sciences Fulda, 35 Marquard Str., Fulda 36039, Germany

Submission date: October 30, 2014; Acceptance date: February 8, 2015; Publication date: February 11, 2015

\begin{abstract}
Background: In December 2007, the European Regulation (EC) 1924/2006 on nutrition and health claims came into force. The European Union wanted to regulate the use of health claims on products. An online survey was carried out to evaluate the situation, particularly of small and medium-sized companies, dealing with the new regulation.
\end{abstract}

Methods: The online survey on health claims was conducted with 16 enterprises. To underline the findings a SWOT (Strength, Weaknesses, Opportunities, Threats) analysis was made of the nutrition and health claims regulation regarding small and medium-sized companies in the European food and drink market.

Results: The findings of this study indicated that the European Union did a step in the right direction. Most companies defined the decent competition, the simplified trade within the inner-European market, and the consumer protection as positive aspects. The biggest threat is seen in false investment conditioned by the limited research and development budgets, especially of small and medium-sized enterprises, and the cost intensive scientific evaluation to reach an authorized health claim.

Conclusions: Overall, there are several strengths and opportunities speaking for SMEs and health claims in the near future. The most promising ones are the publishing of the new European Union Register of Nutrition and Health Claims and the learning effects that will occur. The biggest threat is, and will remain to be, false investment and the possible loss of a lot of money. Nevertheless, health claims for small and medium-sized enterprises will inevitably be the future to keep the European food and drink market competitive.

Keywords: health claims, European Legislation, SME

BACKGROUND: Almost no other topic has put the food industry into such an excitement as the European Regulation (EC) 1924/2006 on nutrition and health claims [1]. In 2005, the 
Nielsen Company already conducted an online survey on "Consumer Attitudes Towards Functional Foods \& Organics". They found out that 27 percent of the asked Europeans purchase cholesterol reducing oils and margarines regularly. However, 42 percent of the Europeans interviewed do not buy cholesterol reducing oils and margarines because they do not believe in the additional health benefits of these products [2]. "As the findings indicate, lack of awareness, availability or even credibility are real barriers to the purchase of Functional Food products and the health benefits they promote" [2]. The lack of credibility is the most interesting part of these statements- keeping in mind the Regulation on health claims. The companies with health claims on their products have to prove their "credibility." They have to justify their claims with scientific data; otherwise, the advertising of such products will be forbidden [3].

Meanwhile, the Nutrition and Health Claims Regulation (NHCR) is discussed with many different viewpoints. Consumer centers and non-governmental organizations praise the European Commission for its ambitioned attempt to protect the consumers from advertising frauds [4,5]; legal representatives criticize the requirements for applicants as unclear [6]; small and medium-sized enterprises (SMEs) see a problem for possible innovations in the sector of healthy food products, especially the unclear regulatory definition of "health food," (such as botanicals, that are seen as a limiting factor) [7].

Due to the ongoing discussions, the question about SMEs emerges. They account for 52 percent of the turnover, 64 percent of the employment of the European food and drinking manufacturing sector (F\&D industry; tobacco industry excluded), and they also represent 283,000 companies, which are 99.1 percent of the F\&D industry [8]. This group cannot be excluded and the questions arose. What are opportunities and what are threats? Is it even possible for SMEs to pass the tight control of the European Food Safety Authority (EFSA)? Is it the future reality, or will it just be a utopian dream?

\section{METHODS:}

Online Survey: The method applied for the data collection was a survey in the form of an online questionnaire with 15 questions - some of them closed and some half-closed.

The categorization of the size of the company was made according to the European Commissions Recommendation of May 6, 2003, concerning the definition of micro, small, and medium-sized enterprises [9]. It should be noted that three large companies participated in the online survey. Due to the low participation rate, the responses of these companies were included. The overall sample size was $16(n=16)$. The participating companies had different main product categories from all over the F\&D industry. Fifty-six percent of the companies stated that they did not use nutrition or health claims on their products before the NHCR entered into force. Forty-four percent used nutrition and health claims beforehand.

The outcome of the online survey cannot be classified as representative. With regard to the basic population, too little of the companies answered the questionnaire. Furthermore, the basic population as well as their product categories was randomly chosen; however, it is not the same as in the F\&D Industry. Nevertheless, the outcome can provide an overview of the current situation and the problems companies have to face due to the NHCR.

SWOT analysis. A SWOT analysis was used to evaluate the need for health claims for SMEs. First, the internal factors, (strengths and weaknesses), and second the external factors, (opportunities and threats), were evaluated. 


\section{RESULTS:}

Online Survey: The results of the online survey will be summarized. The following categorization of the survey is used:

- reaction to the NHCR;

- incurred costs due to the NHCR;

- influence of the NHCR on new product developments (NPDs);

- assessment of the NHCR.

Reaction to the Nutrition and Health Claims Regulation: The companies could define their reaction to the Regulation by giving multiple answers. Sixty-seven percent stated that their company changed recipes of products, and 33 percent agreed that they did additional analysis of the nutritional value of their products. Thirty-three percent stated other measures taken by their companies. Those measures were that the companies had to work actively to reach a potential health claim; the workload of the employees responsible for the NHCR in the company increased drastically, (but still there is no planning certainty); advertising messages and the internet presence were changed to be in line with the Regulation.

Information about the NHCR was gathered with the use of different resources. The internet, associations, and the participation in congresses were the most selected choices with 78 percent, followed by law firms and the German Federal Office of Consumer Protection and Food Safety with 67 percent and the EFSA with 56 percent. Universities, associated companies, business consultancies, and industry associations play minor roles.

Incurred costs due to the Nutrition and Health Claims Regulation. One focus of the survey was on the costs occurred due to the NHCR. Sixty-two and a half percent of the respondents agreed on the fact that the NHCR caused additional costs within their companies. Nevertheless, 37.5 percent negated this point.

The next question served to specify the occurred costs within the companies (Figure 1). Multiple answers were possible for this question. With 80 percent, the largest amount incurred because of the demands for external legal advisers. Fifty percent of the interviewed companies performed additional analyses of nutritional value. Additional personnel costs and the realization of scientific studies were factors for 30 percent of the participants, and 20 percent stated other points, including the destruction of product labels or advertising material.

Figure 1. Measures causing costs due to the Nutrition and Health Claims Regulation $(\mathrm{n}=10)$

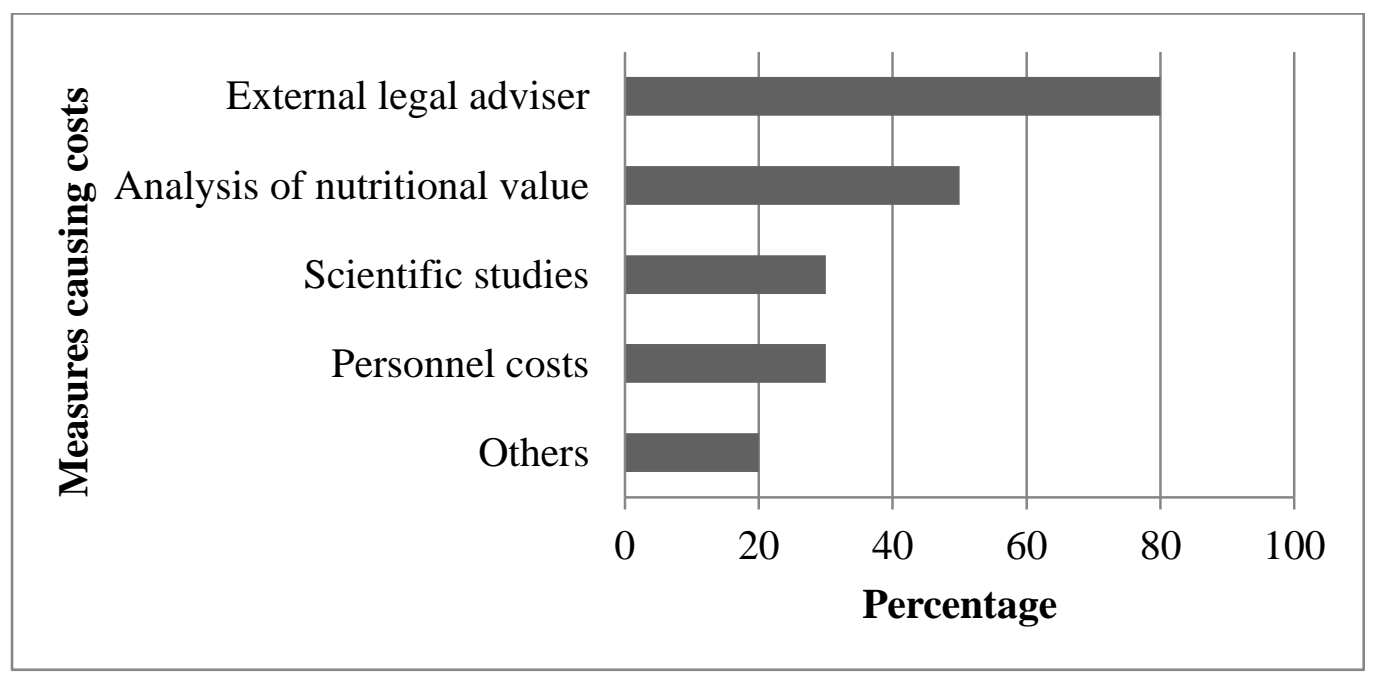


In addition to the specification of the costs, the participants were to classify their company according to the amount of expenses spent since the NHCR came into force (Figure 2). Six groups of spent amounts were prepared, but only three were chosen. Four companies spent amounts between 1,000 and 10,000 euros. Two companies each chose the amounts lying between 100,001 and 500,000 euros, and between 500,001 and 1,000,000 euros. Not chosen were the groups from 10,001 to 50,000 euros, from 50,001 to 100,000 euros, and above $1,000,001$ euros.

Figure 2. Amount of expenses due to the Nutrition and Health Claims Regulation $(n=9)$

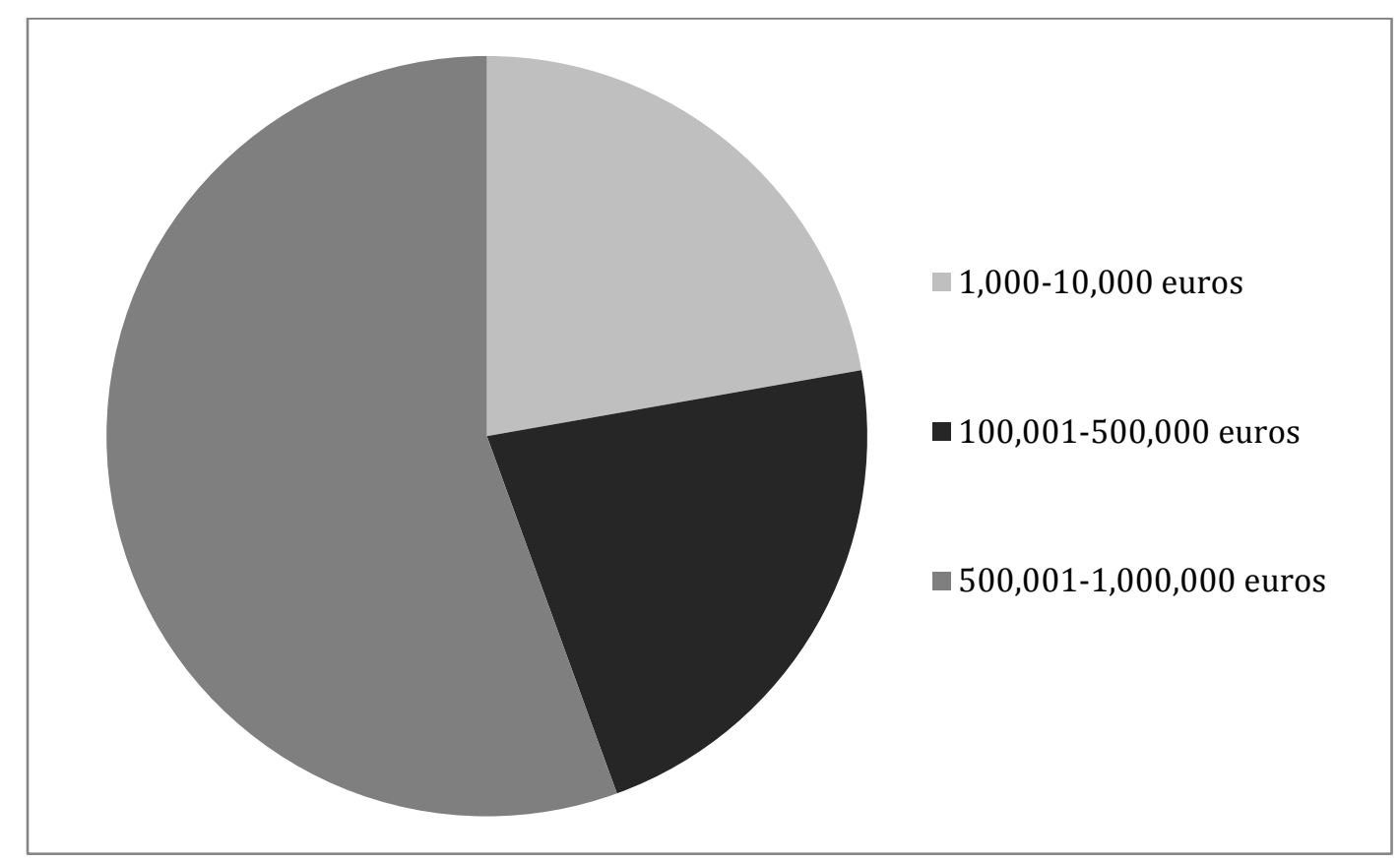

Influence of the Nutrition and Health Claims Regulation on new product developments: Another important point of the online survey was the question about the influence of the NHCR on NPDs of the companies. Most of the participants - 62.5 percent - answered that the NHCR had a direct influence on NPDs within the company, even though 37.5 percent negated the question of the influence on NPDs.

Most of the time, the form of the influence was characterized as negative in terms of delayed or impeded NPDs - with 60 percent. Forty percent did describe other influences the NHCR will have in the future. For example, it was posited that food regulatory requirements will be tested in an early stage of the development of new products. There is also the possibility that there will not be any health related claims on new products. New products can be developed especially for specific, already authorized claims. None of the participants thought the form of influence was positive on NPDs.

Assessment of the Nutrition and Health Claims Regulation: This part gives an overview of the assessment of the NHCR from a business' perspective. Sixty percent assessed the NHCR, in general, as positive and 40 per cent as negative. Both groups were able to define positive as well as negative aspects of the Regulation. They were able to give multiple answers. Sixty-four percent stated that uniform rules lead to a more decent competition, and 57 percent stated that these harmonized rules simplify the cross-border sales and distribution within the inner-European market. Half of the answering participants think the Regulation 
strengthens consumer protection and makes consumer information easier. Seven percent chose "others" and defined one positive aspect for products or ingredients with authorized health claims as their competitive advantage.

Ninety-three percent criticized the requirements for the scientific verifiability of potential health claims as too strict. The legal interpretation being too vague was stated by 47 percent, and 40 percent of the participants' think the NHCR leads to unreasonable restraints of competition. Twenty percent mentioned other critical points such as big companies with specified legal departments having an advantage over SMEs, especially regarding the uncertainty with legal interpretation. It is easier to abandon health claims on products than to pay for charges. Another point of view is that the consumer does not understand the regulation; therefore, the advertising effect is unpredictable. Also posited was that the procedure to get a health claim authorized is too costly and too time consuming. Its return on investment is still unsure.

Next, the future strategies of companies regarding the NHCR will be surveyed. Only 40 percent of the participants do not plan to react to the NHCR. In contrast, 60 percent plan to do so. This 60 percent defined their strategies, including that none of them want to abandon nutrition and health claims or use more general advertising messages instead. Also ,however, 50 percent plan to further analyze the nutritional value. Twenty-five percent will change the recipes of their corresponding products.

Two answers were added as future steps that will be taken: to develop new products and to wait for the juristically reasonable decision concerning a requested health claim, and to clarify the future strategy accordingly.

The last part of the survey was questioning opportunities and threats the participants expect for their companies. They were able to give multiple answers. Forty-four percent identified one opportunity in the future market growth and, therefore, an increase in sales and turnover for their health-related products. Thirty-three percent think that a product with an authorized health claim will lead to a competitive advantage, and 44 percent answered with other non-prepared statements. One participant sees an opportunity in the certainty of the product labeling and stated that clients or customers can be advised more easily. Another participant does not see any chance for its company because the requirements are too strict and too expensive. One answer was that it cannot be foreseen which consequences the NHCR will have for the company.

Fifty percent see a threat in the competitive disadvantage their companies will have without "health claim products". Thirty-three percent think they will have market share losses, decline in sales, and turnover. Twenty-five percent wrote other statements, such as the fact that most of the products on the market will be advertised with easily accessible health claims; therefore, there will be an overabundance of healthy claimed products and no advantage for products with highly scientific claims. There is one participant that does not see any threat for its company at all.

SWOT analysis. In the following part, the need for health claims for SMEs will be discussed with the use of a SWOT analysis. First, the internal factors, strengths and weaknesses, will be explained, followed by the analysis of the external factors, opportunities and threats. Table 1 provides an overview of the SWOT analysis outcome. 
Table 1. SWOT analysis of health claims for small and medium-sized companies

\begin{tabular}{llll}
\hline Strengths & Weaknesses & Opportunities & Threats \\
\hline - Knowledge about & - Low level of & - Trade inside and outside & - Increased power of \\
regional/cultural & investment in R\&D & the EU & food retailers \\
products and eating & - False investment means & - Increasing support of & - Complexity of the \\
habits & existential problems & EFSA and European & NHCR \\
- Specialized in & - Lack of skilled & Commission & - Increased \\
products and markets & employees with & - Consumer demand for new & competition from \\
- Strong ability to add & specialized knowledge & products (nutritionally & other parts of the \\
value to products & (e.g. about legal & healthy, convenience, & world - global players \\
- Work together with & requirements) & regional, etc.) & - Aging and declining \\
big companies and & - Focus on just & - Increased segmentation of & European population \\
universities & authorized health & markets into target groups & affecting employment \\
- Use of already & claims & with specific needs (e.g. & and markets \\
authorized health & & elderly people) & \\
claims & & & \\
- Strong ability to & & & \\
differentiate products & & & \\
and company & & & \\
- Communicate and & & & \\
influence eating culture & & & \\
\hline
\end{tabular}

The bullet points are listed descending in importance. Points in bold are explained in the following text.

Strengths: One of the biggest strengths of SMEs regarding the NHCR is their knowledge on local eating habits and regional product specialties. Compared to the United States (U.S.), the cultural differences in tastes, food habits, and preferences in Europe differ more between countries, Federal States, and smaller regions [10]. The existence of many SMEs with highly specialized products is important for the picture of the European F\&D market; examples are the highly diversified beer market in Germany or the olive oil markets in Italy and Spain. Even though consumers find cheap, plagiarized products in supermarkets, they prefer local products. Due to the small number of consumers, the production costs are higher for SMEs, but the local consumers are willing to pay for that added value [10]. The companies are already highly specialized in products and markets. With this advantage, a production of niche products is possible.

Another possibility to exploit is the cooperative work with other SMEs, bigger companies, and universities. One example is the product Fruitflow [11], which succeeded because of the work of an interdisciplinary team of scientists and business specialists [12]. The network means a win-win situation for every participant of the cooperation. For example, a small enterprise works with a big company; on the one hand, the big company could finance clinical studies and, therefore, add value to the small enterprise; on the other hand, the small company could use its local knowledge to create a regional top seller and, therefore, add value with an increased regional prominence of the big company [13].

SMEs can also use already authorized claims of the European Union Register of Nutrition and Health Claims (Register). There is no need for an own health claim by all means, especially if they have a good carrier product within their product portfolio, such as yogurt or bread [14]. 
Weaknesses: The most significant negative aspect of the NHCR regarding SMEs is the high expenses involved to get a health claim authorized. Scientific evidence of the highest level is required [15]. Clinical studies are needed, and they can be quite costly. Multi-corporate enterprises such as Danone have a high research and development (R\&D) budget each year. The company's R\&D department has more than 1,400 scientists working with a budget of 276 Million euros on 160 clinical trials [16]. How much Danone invests in research on health claims is hard to approximate. However, an example of money invested is given by Danone's brand Milupa, who invested five to ten million euros for a potential health claim. As expected, the main part of the money was spent for clinical studies [17]. In comparison to Danone, most of the SMEs have limited R\&D budgets [13].

In the future, many companies will rely on already authorized health claims. That could be seen as weakness in two points. First, new promising product innovations would be blocked, and the chance for a possible competitive advantage would be abandoned. Secondly, consumers could be "overloaded" by continuously used health claims, and the added value of those claims might decline.

Opportunities: The equal conditions to use health claims will lead to a better opportunity to trade within and outside the European Union. Banse and Wijnands described the fact that "European prices of export products are higher than the prices of imports" [10]. This and good cooperation, especially with the U.S., are promising conditions for the future of health claims; Fruitflow is already sold and accepted worldwide [11].

The support for companies striving for an authorized health claim is improving. Up to now, there have been eight guidance documents published on EFSA's webpage, and there is an applications helpdesk. It includes the "frequently asked questions" and the possibility to ask individual questions directly to the EFSA [18,19]. Furthermore, learning effects will occur. SMEs can check authorized health claims and their application forms. This will help to realize scientific studies of the required standard and to create applications more precisely.

Finally, healthy nutrition is a major issue for policy makers as well as for consumers. Claiming health will continue to be a favorable added value for both of them [20].

Threats: One big threat is the increased power of food retailers. There are only a few big food retail companies who dictate the market [21]. They have not only power over the consumers but also over the suppliers and F\&D manufacturers [22]. SME products have to compete with globally known brands and private labels for shelf spaces [23]. The companies supplying supermarkets can be switched very easily due to the highly standardized product range sold in supermarkets today. The position of SMEs is very weak against big retailers [10].

Then there is an unbroken uncertainty regarding the practicability due to the complexity of the NHCR. This complexity is often a problem for SMEs regarding European legislation [24].

\section{DISCUSSION:}

The overall objective of this study was to identify whether the NHCR can be used by SMEs in the future. Furthermore, not only were the hurdles which have to be taken while working with the NHCR evaluated but also the opportunities and chances that are given to SMEs 
because of it. The findings of this research and its derived conclusions build a preliminary assessment of the current situation of SMEs regarding the NHCR.

Half of the companies participating in the online survey stated that they reacted actively since the NHCR entered into force. The other half did not react at all, maybe because some participating companies are more influenced by the Regulation, e.g. producers of pharmaceutical and nutritional supplements, than others, e.g. suppliers of fruit or vegetables. A second explanation could be that by the time the survey was carried out, some companies did not know exactly to which extent their products were influenced by the restraints. Even for law specialists it is still hard to say whether an advertising message falls under the NHCR or not. It is understandable that the companies who answered with a reaction on the Regulation did mainly clarify the legal conformity of their products and advertising messages.

Information on the NHCR was gathered with the use of different resources, which underlines the fact that the complexity of the Regulation makes the reliability on just one source impossible; the internet, associations, and congresses were used by almost all participants. But expandable is the low level of information gathered via EFSA's webpage, which is especially important due to the guidance documents and the helpdesk $[18,19]$. This was enhanced particularly to strengthen SMEs accomplishing art. 15 par. 5 of the NHCR [1], where it states the following: "The European Commission, in close cooperation with the European Food Safety Authority, shall make available appropriate technical guidance and tools to assist food business operators, in particular SMEs, in the preparation and presentation of the application for scientific assessment." Unfortunately, it seems that the support is not as tangible as it should be. The guidance documents are still complicated, and the help of expensive consultants is inevitable.

The networking with other companies or universities plays a minor role for the participants of the online survey, although this was identified as a possible strength within the SWOT analysis. The continuously changing framework in which the Regulation is embedded makes this inevitable. To guarantee best possible results for the authorization of a health claim, it can be derived that an interdisciplinary team should be formed. This should be composed of several scientists, for the necessary literature research and the realization of studies, a law consultant, for the assessment of the wording of the claim and its legal conforming, and, of course, an employee of the company competent for the field of health and nutrition.

More than half of the companies agreed that the NHCR has an impact on NPDs within their companies. They specified the influence as negative in terms of "delayed" or "impeded" NPDs. This indicates that not only SMEs hesitate to put NPDs on the market because of the threat of false investment. Big companies also tend to wait to get more information. Overall, the NHCR tends to obstruct NPDs and innovations in the "healthy food" sector. The situation is especially critical for SMEs, which represent 99.1 percent of the F\&D industry. The European Commission is actually well aware of the important SME sector; in preamble 33 of the NHCR [1], it reads that "SMEs represent an important added value to the European food industry in terms of quality and preservation of different dietary habits. In order to facilitate the implementation of this Regulation, the EFSA should make available appropriate technical guidance and tools, in due time, especially for SMEs." Disregarding the importance of SMEs within the European F\&D market will lead to a huge distortion of competition in the near future, which will not only negatively influence the sector but also the final consumer. 
This work already evaluated two inhibitors: the limited R\&D budget, especially of SMEs, and the cost intensive scientific evaluation. The authorization of a health claim is expensive, which can also be indicated by the examples of Danone's brand Milupa, which invested five to ten million euros for a potential health claim [17], and Provexis the inventor of "Fruitflow". According to the explained definition of SMEs, Provexis can be defined as a small company [25]. Nevertheless, the British company invested two million British Pounds for eight human studies to get their claim authorized [26].

Furthermore, four participants of the online survey stated that the amount of expenses due to the Regulation was between 100,001 and 1,000,000 euros. Five participants classified themselves among the group of 1,000 to 10,000 euros that matches the high group of companies investing in external legal advisors and in extra analyses of the nutritional value of their products. With the publishing of the authorized health claims within the Register [27], this group might strongly increase. Especially with the help of scientific and legal consultants, the authorized claims can be used quite easily compared to the long authorizing procedure of an own health claim. The segment between 10,001 and 100,000 euros is completely missing, indicating that once the decision to get a health claim authorized is made, the companies have no choice but to invest in expensive studies. At the moment, the possibility of a "low-cost" strategy is simply non-existent.

Another relevant point concerns the threat of false investment. If a health claim was submitted and fails, the statements given by the national authorities and by the EFSA would already help to re-organize and enhance the study designs. The company is given the opportunity to change the application- the invested money is not gone for good. Nevertheless, companies still need a long wind to reach their goal for an authorized health claim, and this will not change in the foreseeable future.

Although the Regulation's impact on NPDs is mostly seen as negative, 60 percent of the companies assessed the NHCR overall as positive. The decent competition, the simplified trade within the inner-European market, and the consumer protection were defined as positive aspects. These answers correlate with the goals of the European Commission and were defined as opportunities within the SWOT analysis. Almost all participants in the survey see the biggest negative impact in the high requirements of the scientific substantiation. As already mentioned, it is very cost intensive to fulfill the requirements of the EFSA, almost comparable to those of medical products [28]. This raises the question of the proportionality. Is there such a big threat of "unhealthy food" claimed as "healthy food"? Would it not be sufficient to have, for example, a health claim label established as with the case of the "Food for Specific Health Uses" (FOSHU) label in Japan [29]? Another strategy could have been the system in the U.S. where the Food and Drug Administration (FDA) has different authorization processes for health claims. The FDA differentiates between authorized health claims meeting Significant Scientific Agreement, their scientific standards are comparable to those required by the EFSA, and other claims such as the qualified health claims and structure/ function claims which can be based on less scientific evidence as long as the claims do not mislead the consumers [30]. That would have saved the money of taxpayers and companies, and authorizing authorities could have had time to slowly adopt the regulatory changes.

Half of the participants see negative effects due to the vague legal interpretation. One participant even stated that this leads to an advantage for big companies with highly skilled legal departments. These statements are in line with the findings of the SWOT analysis, 
which identified the rising competition of companies for skilled workers and the complex European legislation as two external threats influencing SMEs.

The last part of the survey can be regarded as a forecast given by the participants - what opportunities and what threats will occur due to the NHCR? The companies' biggest fear is competitive disadvantage, such as market share losses and declining sales and turnovers, due to the NHCR. In contrast to that chances are seen in the future market growth, which could be defined as a market growth in the sector of "functional foods" or a market growth due to the declined trade barriers within the European market. The growth opportunities, increased segmentation, and simplified trading conditions were also indicated by the SWOT analysis. Another opportunity is the increase in sales and turnover; and 33 percent see the chance of a competitive advantage for products bearing health claims. This is a statement of particular importance because more health claims and, therefore, more companies with a competitive advantage, could mean a higher competitive advantage of the European F\&D industry overall.

\section{CONCLUSIONS:}

The main part of this work was the online survey clarifying the status of companies dealing with the NHCR. The online survey was carried with sixteen participants in 2012. The outcome of it cannot be classified as representative, but it can give an overview about the current situation and problems companies have to face due to the NHCR. A literature research led to the outcome of the SWOT analysis of the NHCR regarding SMEs.

The online survey indicated that half of the companies did react to the NHCR with clarifications of the legal conformity of their products and of advertising messages. Information was gathered with the use of several sources, whereas some sources should be used more precisely, (such as the EFSA webpage and its guidance documents). The networking with other companies and universities should also be extended, which would lead to a win-win situation for all participants. Furthermore, an interdisciplinary team of experts should be formed, including scientists, a lawyer, and a competent employee of the company: only then is there a chance to get a health claim authorized.

Most companies defined the influence on NPDs as negative in terms of delaying and impeding. This is in contrast to the goals of the European Commission, which sees the importance of SMEs for the industry and wants them to be a part of the innovation processes. The two evaluated inhibitors are the limited $R \& D$ budget and the cost-intensive scientific evaluation. Most companies fear the threat of false investment because they see the authorizing procedure of health claims as very complex and uncertain. This threat might decline, especially when looking at the published Register. The use of already authorized claims is easier than to authorize an own health claim.

Sixty percent of the companies assessed the NHCR overall as positive. The better trading opportunities and the consumer protection were seen as the most positive impacts and correlate with the goals of the European Commission. Overall, SMEs are not willing to lack health claims completely on their products, although there are some problems they have to face. It is predictable that learning effects will occur and will lead to more equal conditions. However, multi-corporate companies still have the advantage the bigger R\&D budget. The required cost-intensive and strict scientific substantiation is identified as the biggest overall negative effect of the NHCR for SMEs. 
On the one hand, companies see their opportunities in the future market growth, the increase in sales and turnovers, and the competitive advantage for products bearing health claims. On the other hand, they see threats in competitive disadvantage, market share losses, and declining sales and turnovers. The controversial answering of these two questions identified a heterogeneous group of participants and underline the uncertainty of the legal framework the companies have to face.

Overall, there are several strengths and opportunities speaking for SMEs and health claims in the near future. The most promising ones are the publishing of the Register and the learning effects that already occurred. The biggest threat is, and will remain to be, false investment and the possible loss of a lot of money. Nevertheless, health claims for SMEs will inevitably be the future to keep the European F\&D market competitive.

\section{RECOMMENDATIONS:}

In this part some recommendations are made to improve the applicability of the NHCR for SMEs. Three groups are significant: first, SMEs and their competent business operators, secondly, research as a provider of knowledge, and thirdly, the European Commission, the competent National Authorities, and the EFSA as an influencer of the external factors.

SMEs should exploit their strengths and should take and explore opportunities given by the Authorities. An example is the strength of networking with other companies and universities; this could save a lot of money and would decline the threat of false investment because it offers the chance to outsource the expensive scientific studies.

Research should be focused more precisely on the influence of the NHCR on NPDs, especially now that the Register is online. Additionally, it could be analyzed, if the perception of the consumers changed. Is the threat of an "overload" existent due to the Register? For further research concerning SMEs and the NHCR, it is recommended to target companies with and without an already assessed health claim separately, (ideally including the question if the health claim was authorized or rejected). Expert interviews offer, furthermore, a promising opportunity to get detailed, insightful information about the authorizing procedures.

Finally, the European Commission, the National Authorities, and the EFSA should ease the availability of necessary data for SMEs, ultimately on one webpage. This would make the authorization process easier for all participants. An official center of consulting could offer pre-checks, which would additionally speed up and enhance the process. An extra fee could cover the additional costs. The authorities should support and encourage SMEs to reach their own health claims. A group of 99.1 percent is too large and too important to be overlooked.

Competing Interests: The authors have no financial interests or conflicts of interest.

Authors' Contributions: All authors contributed to this study.

Abbreviations: SWOT, Strength, Weaknesses, Opportunities, Threats; NHCR, Nutrition and Health Claims Regulation; SMEs, Small and Medium-sized Enterprises; F\&D industry, European Food and Drinking Manufacturing Sector; EFSA, European Food Safety Authority; NPDs, New Product Developments; U.S., United States; Register, European Union Register of Nutrition and Health Claims; R\&D, Research and Development 
Acknowledgements: The authors would like to thank all participants of the online survey.

\section{REFERENCES:}

1. European Parliament and Council: Regulation (EC) No 1924/2006 (amended in 2008). In Official Journal of the European Union 2006. [http://eurlex.europa.eu/LexUriServ/LexUriServ.do?uri=CONSLEG:2006R1924:20080304:EN:PDF] (State: 10/29/2014).

2. Nielsen: Consumer Attitudes Towards Functional Foods \& Organics. 2005. [http://at.nielsen.com/site/documents/Functional_Organics_Nov05.pdf] (State: 08/05/2014).

3. Bundesinstitut für Risikobewertung (Federal Institute for Risk Assessment): Health Claims. 2014. [http://www.bfr.bund.de/de/health_claims-9196.html] (State: 10/29/2014).

4. Verbraucherzentrale Bayern (Consumer Advice Centre of Bavaria): Lebensmittel mit Gesundheitsversprechen: EU dampft die Flut der Werbeaussagen ein. 2014. [http://www.verbraucherzentrale-bayern.de/lebensmittel-mit-gesundheitsversprechen] (State: 10/29/2014).

5. Groß C: Foodwatch zu Health Claims Liste gesundheitsbezogener Aussagen EUKommission. 2012. [http://www.presseportal.de/pm/50496/2259919/foodwatch-zu-healthclaims- liste-gesundheitsbezogener-aussagen-eu-kommission] (State: 10/29/2014).

6. Hagenmeyer M and Hahn A: Die geheimen Rezepturen der EFSA. Zeitung für Stoffrecht (StoffR) 2010, 6:261-277.

7. Koch A, Brandenburger S, Türpe S, Birringer M: The need for a legal distinction of nutraceuticals. Food and Nutrition Sciences 2014, 5 (Suppl 10):905-913.

8. FoodDrinkEurope: Data \& Trends oft he European Food and Drink Industry 2013-2014. 2014.

[http://www.fooddrinkeurope.eu/uploads/publications_documents/Data_Trends_of_the_Eur opean_Food_and_Drink_Industry_2013-2014.pdf] (State: 10/29/2014).

9. European Commission: Commission Recommendation of 6 May 2003 concerning the definition of micro, small and medium-sized enterprises. In Official Journal of the European Union 2003.

[http://eurlex.europa.eu/LexUriServ/LexUriServ.do?uri=OJ:L:2003:124:0036:0041:EN:PDF] (State: 10/29/2014).

10. Banse $M$ and Wijnands $J$ (2007): Key success factors and policy scenarios. In Competitiveness of the European Food Industry: An economic and legal assessment. Edited by Wijnand J, van der Meulen B, Poppe K. 2007:251-272. [http://ec.europa.eu/enterprise/sectors/food/files/competitiveness_study_en.pdf] (State: 10/29/2014).

11. Provexis plc: Fruitflow. 2014. [http://www.provexis.org/fruitflow/] (State: 10/29/2014).

12. Bouckley, B: Provexis keeps Fruitflow powder dry, axes UK R\&D facility. 2011. [http://www.beveragedaily.com/Manufacturers/Provexis-keeps-Fruitflow-powder-dry-axesUK-R-D-facility] (State: 10/29/2014).

13. Gueimonde M and Lathinen SJ: 17. Probiotics and Health Claims: How to Be Met by SMEs? In Probiotics and Health Claims. Edited by Kneifel W and Salminen S. Oxford, UK: WileyBlackwell; 2011.

14. Wills JM, Storcksdieck S, Kolka M, Grunert KG: European consumers and health claims: attitudes, understanding and purchasing behaviour. Proceedings of the Nutrition Society 2012. 71(Suppl 2):229-236.

15. Meyer F: Fragen \& Antworten: Health Claims-Verordnung. Hamburg: Behr's Verlag; 2007.

16. Danone S.A.: Our research at a glance. 2014. [http://www.danone.com/en/for-all/researchinnovation/our-research-at-a-glance/] (State: 10/29/2014).

17. Düthmann C: Im Bann der Bürokraten. Lebensmittel Zeitung Spezial 2008, Vol. 1. 
18. European Food Safety Authority: Guidance for applicants on health claims. 2014. [http://www.efsa.europa.eu/en/nda/ndaguidelines.htm] (State: 10/29/2014).

19. European Food Safety Authority: Applications helpdesk. 2014. [http://www.efsa.europa.eu/en/applicationshelpdesk.htm] (State: 10/29/2014).

20. Menrad K and Sparke K: Consumers' attitudes and expectations concerning Functional Food. 2006.[http://www.wzstraubing.de/fachhochschuleweihenstephan/download/bericht_functiona lfood_1.pdf] (State: 10/29/2014).

21. Metro AG: Metro Retail Compendium. Data, figures and facts. Europe. The leading trade and retail companies. The 10 largest food retailers in Europe, 2012. 2014. [http://www.metroretailcompendium.de/en/data_figures_facts.html\#!376] (State: 10/29/2014).

22. Harvey M: The rise of supermarkets and asymmetries of economic power. In Supermarkets and agri-food supply chains: Transformations in the production and consumption of foods. Edited by Burch D and Lawrence G. Cheltenham Glos: Edward Elgar Publishing Ltd; 2007:51-73.

23. OECD (The Organisation for Economic Co-operation and Development): Policy Roundtables. Competition Issues in the Food Chain Industry. 2013. [http://www.oecd.org/daf/competition/CompetitionIssuesintheFoodChainIndustry.pdf] (State: 10/29/2014).

24. Brandenburger S and Birringer M: Milliardenumsätze mit „Health Claims“. Kleine und mittelständische Unternehmen bleiben außen vor. Ernährungs Umschau 2014, 8:442-446.

25. Provexis plc: Annual report and accounts 2013. 2013. [http://www.provexis.org/wpcontent/uploads/2011/12/Provexis-plc-annual-report-31-Mar-13.pdf] (State: 10/29/2014).

26. Kutter S and Donner S: Und es geht doch: Essen als Therapie. Wirtschafts Woche 2010, 42:108.

27. European Commission: EU Register of nutrition and health claims made on foods. 2013. [http://ec.europa.eu/nuhclaims/] (State: 10/29/2014).

28. Greifender S: Nährwert- und gesundheitsbezogene Angaben bei Lebensmittel in Deutschland und Europa. Bayreuth: PCO Verlag; 2009.

29. Japanese Ministry of Health, Labour and Welfare: Food for Specific Health Uses (FOSHU). 2014. [http://www.mhlw.go.jp/english/topics/foodsafety/fhc/02.html] (State: 10/29/2014).

30. U.S. Food and Drug Administration: Guidance for Industry: A Food Labeling Guide (8. Claims)2013.[http://www.fda.gov/Food/GuidanceRegulation/GuidanceDocumentsReg ulatoryInformation/LabelingNutrition/ucm064908.htm] (State: 10/29/2014). 